\title{
O CONSUMO DE FLÚOR EM ÁGUAS SUPERFICIAIS E TERRITÓRIOS DE RISCO PARA A SAÚDE HUMANA NA REGIÃO NORDESTE DO PARANÁ
}

\author{
José Paulo Peccinini Pinese \\ Universidade Estadual de Londrina (UEL) \\ Departamento de Geociências, CEGOT, Londrina, PR, Brasil \\ pinese@uel.br \\ Ângela Golono de Deus \\ Universidade Estadual de Londrina (UEL) \\ Pós-Graduação em Geografia, Londrina, PR, Brasil \\ angelagolono@gmail.com \\ Lúcio José Sobral da Cunha \\ Universidade de Coimbra (UC) \\ Departamento de Geografia e Turismo, CEGOT, Coimbra, Portugal \\ luciogeo@fl.uc.pt \\ Willian da Silva Santos \\ Universidade Estadual de Londrina (UEL) \\ Pós-Graduação em Geografia, Londrina, PR, Brasil \\ willian.geo2@hotmail.com \\ João Carlos Alves \\ Universidade Estadual de Londrina (UEL) \\ Departamento de Química, Londrina, PR, Brasil \\ jcalves@uel.br
}

\begin{abstract}
RESUMO
No Nordeste do Paraná se assinalam teores de fluoretos em águas superficiais de abastecimento público, acima dos recomendáveis para a saúde humana $\left(\geq 0,8 \mathrm{mg} / \mathrm{L}\right.$ de $\left.\mathrm{F}^{-}\right)$ Tendo em vista que a ingestão de teores diários de flúor fora do intervalo de 0,6 a 0,8 mg/L de $\mathrm{F}^{-}$, seguindo o rigor da lei brasileira, possibilita a geração de patologias como a cárie e a fluorose, se objetiva nessa investigação apontar localidades onde as concentrações naturais de flúor obtidas em drenagens, delimitem áreas de risco para a saúde humana pela ingestão direta ou fluoretada. Para tanto, duzentas amostras de águas brutas georreferenciadas foram coletadas (2016-2018) em bacias hidrográficas que abastecem a região, sendo todas analisadas quimicamente para flúor através da técnica da Potenciometria Direta (teores até 1,2 mg/L). A espacialização dos dados, indica municípios potencialmente propensos ao risco de fluorose dental cujos picos de teores se alinham na direção SW-NE, como um cinturão de anomalias (Jundiai do Sul, Santo Antônio da Platina e Jacarezinho). Também indicam municípios com risco a cáries. Adicionalmente se constata que novos levantamentos epidemiológicos e hidrogeoquímicos devam ser realizados, sobretudo em águas subterrâneas, para melhor delimitar a abrangência dos riscos e suportar o planejamento da Saúde Coletiva.
\end{abstract}

Palavras chave: Flúor. Riscos. Hidrogeoquímica. Nordeste do Paraná. Saúde Coletiva.

\section{THE INGESTION OF FLUORIDE IN SURFACE WATERS AND TERRITORIES WITH RISK TO HUMAN HEALTH IN THE NORTHEAST PARANÁ REGION}

\begin{abstract}
In the Northeast of Paraná, fluoride levels in surface waters for public supply are above those recommended for human health $(\geq 0.8 \mathrm{mg} / \mathrm{L})$. Within Brazilian law, the daily intake of fluoride levels outside the range of 0.6 to $0.8 \mathrm{mg} / \mathrm{L}$ can facilitate the generation of pathologies such as caries and fluorosis. Thus, the current investigation aimed to identify locations where the natural fluoride concentrations obtained in drainage basins delimit areas of risk to human health through direct ingestion. For this purpose, two hundred georeferenced raw water samples were collected (2016-2018) from hydrographic basins that
\end{abstract}


supply the region, all of which were chemically analyzed for fluoride using the Direct Potentiometry technique $(\leq 1.2 \mathrm{mg} / \mathrm{L})$. The spatialization of the data indicates municipalities potentially prone to the risk of dental fluorosis, with peak levels aligned in the SW-NE direction, representing a belt of anomalies (Jundiai do Sul, Santo Antônio da Platina, and Jacarezinho). The results also specify municipalities at risk for caries. The findings indicate that new epidemiological and hydrogeochemical surveys should be carried out, especially in groundwater, to better delimit the scope of the risks and support the planning of Public Health.

Keywords: Fluorine. Risks. Hydrogeochemistry. Northeast Paraná. Public health.

\section{INTRODUÇÃO}

O flúor destaca-se como o décimo terceiro elemento mais abundante na crosta terrestre, sua abrangência se estende a diversos materiais geológicos e corpos hídricos como ação do intemperismo. Se apresenta em diferentes concentrações que variam devido a um conjunto de fatores, tais como: temperatura, $\mathrm{pH}$, presença ou não de complexos minerais, íons precipitados e coloides, solubilidade de minerais, capacidade de troca iônica de minerais (adsorção em argilominerais), granulometria e o tipo da litologia, bem como o tempo de residência nas águas (MARIMON, 2006).

Em geral, os teores de flúor em águas superficiais brutas são baixos devido a retenção, por exemplo, em partículas coloidais e a autodepuração inerente a cada corpo hídrico, mas não raro, algumas concentrações anômalas são assinaladas podendo ter origem natural (geogênica) ou antrópica (tecnogênica), tanto por acreção como por supressão.

Nos Estados Unidos da América (EUA) na década de 1940, se constatou uma correlação inversamente proporcional entre teores de flúor nas águas de abastecimento público e a ocorrência de cáries (FRAZÃO; PERES; CURY, 2011). Esse fato, naquele país, gerou a adoção do processo de fluoretação que se configura na adição de íons fluoretos em águas naturais distribuídas para consumo humano e animal, se transformando em uma das principais fontes tecnogênicas de concentrações excessivas.

Posteriormente, muitas nações, entre elas o Brasil, também adotaram a fluoretação como forma auxiliar na prevenção de cáries, a qual encontra grande apoio de pesquisadores em saúde bucal até os dias de hoje.

Por outro lado, a anomalia por excessos em fluoretos sob a ótica geogênica, depende substancialmente da ampla variabilidade mineralógica da rocha, merecendo destaque aqueles na forma de fluorita $\left(\mathrm{CaF}_{2}\right)$, fluoroapatita $\left(\mathrm{Ca}_{10}\left(\mathrm{PO}_{4}\right)_{6} \mathrm{~F}_{2}\right)$ e criolita $\left(\mathrm{Na}_{3} \mathrm{AlF} \mathrm{F}_{6}\right)$. Sua liberação em solução, ocorre geralmente através da hidrólise (MARIMON, 2006) devido a interação rocha/água no intemperismo.

Tanto a Organização Mundial da Saúde - OMS (1984) como o Ministério da Saúde (BRASIL, 1976; 2017), apontam que a ingestão diária de águas naturalmente enriquecidas em Flúor ( $\geq 1,5 \mathrm{mg} / \mathrm{L})$ podem gerar patologias como a fluorose dental e óssea.

Considerando que no Nordeste do Estado Paraná se verifica uma extensa área flúor-anômala (Figura 5; MINEROPAR, 2001) e que nas bordas dessa anomalia foram assinalados casos de fluorose dentária (PINESE et al., 2002; PIRES, 2008), se objetiva no presente artigo investigar os teores naturais de fluoretos nas águas das bacias hidrográficas utilizadas no abastecimento público dessa região.

Também se pretende nessa investigação, retratar e delimitar municípios/localidades cujos índices em flúor poderão potencialmente influenciar na saúde humana, transformando-os em áreas de risco quando da sua ingestão direta ou futuramente manipulada (fluoretada) pela população local. Adicionalmente, se espera subsidiar o poder público na indicação destas áreas, nas quais se priorizarão ações do planejamento da Saúde Coletiva e de distribuição de águas que visem minimizar os impactos mencionados.

Embora as águas das Bacias do Cinzas, Itararé, Paranapanema I e II e Tibagi, contidas no nordeste do Paraná, sejam consideradas como de razoável qualidade para consumo, inexistem trabalhos

$\begin{array}{lllll}\text { Caminhos de Geografia } \quad \text { Uberlândia-MG } & \text { v. 22, n. } 81 \quad \text { jun./2021 } & \text { p. 88-105 } & \text { Página } 89\end{array}$


científicos analisando as concentrações químicas destas e suas relações com a toxicidade à saúde humana e animal.

\section{METODOLOGIA}

Para atingir os objetivos propostos, se iniciou a tradicional revisão bibliográfica fundamentalmente direcionada na relação entre ingestão de flúor e os possíveis impactos na saúde coletiva, bem como nas patologias associadas e sua distribuição no Paraná.

Posteriormente nos trabalhos de campo, se efetuou a coleta de duzentas amostras georreferenciadas de águas superficiais in natura (recipiente de $100 \mathrm{ml}$ ) entre os anos de 2016 e 2018, em drenagens das bacias hidrográficas utilizadas para o abastecimento público (Figura 1). A coleta de amostras obedeceu às recomendações técnicas propostas pelo Ministério da Saúde - MS (BRASIL 1976; 2014) e "Protocolo de Coleta e Análise da Amostra de Água" (CECOL, 2014), nas quais se indica o uso de frascos de polietileno, bem como a prática de lavar inicialmente os frascos, pelo menos de três a seis vezes com a água a ser analisada, para evitar contaminantes que possam interferir nos resultados.

Após as coletas no campo os frascos de polietileno foram acondicionados e mantidos em caixa térmica com gelo, até serem transferidos para a câmara fria do laboratório. Para manuseio todos foram precedidos de uma lavagem com tampa, utilizando $\mathrm{HCl}$ e água destilada deixando secar naturalmente.

$\mathrm{Na}$ obtenção dos teores de íons fluoreto empregou-se a técnica da potenciometria direta, na qual são necessários dois tipos de eletrodos - um eletrodo seletivo a íons de fluoreto e um eletrodo de referência de calomelano. Calibrou-se o primeiro aparelho com cinco padrões de concentrações variáveis e posteriormente elaborou-se o gráfico de calibração para obter dados quantitativos das concentrações de flúor em cada amostra de água (FERNANDES et al., 2001).

Figura 1 - Nordeste Paranaense: Pontos de amostragem das águas superficiais.

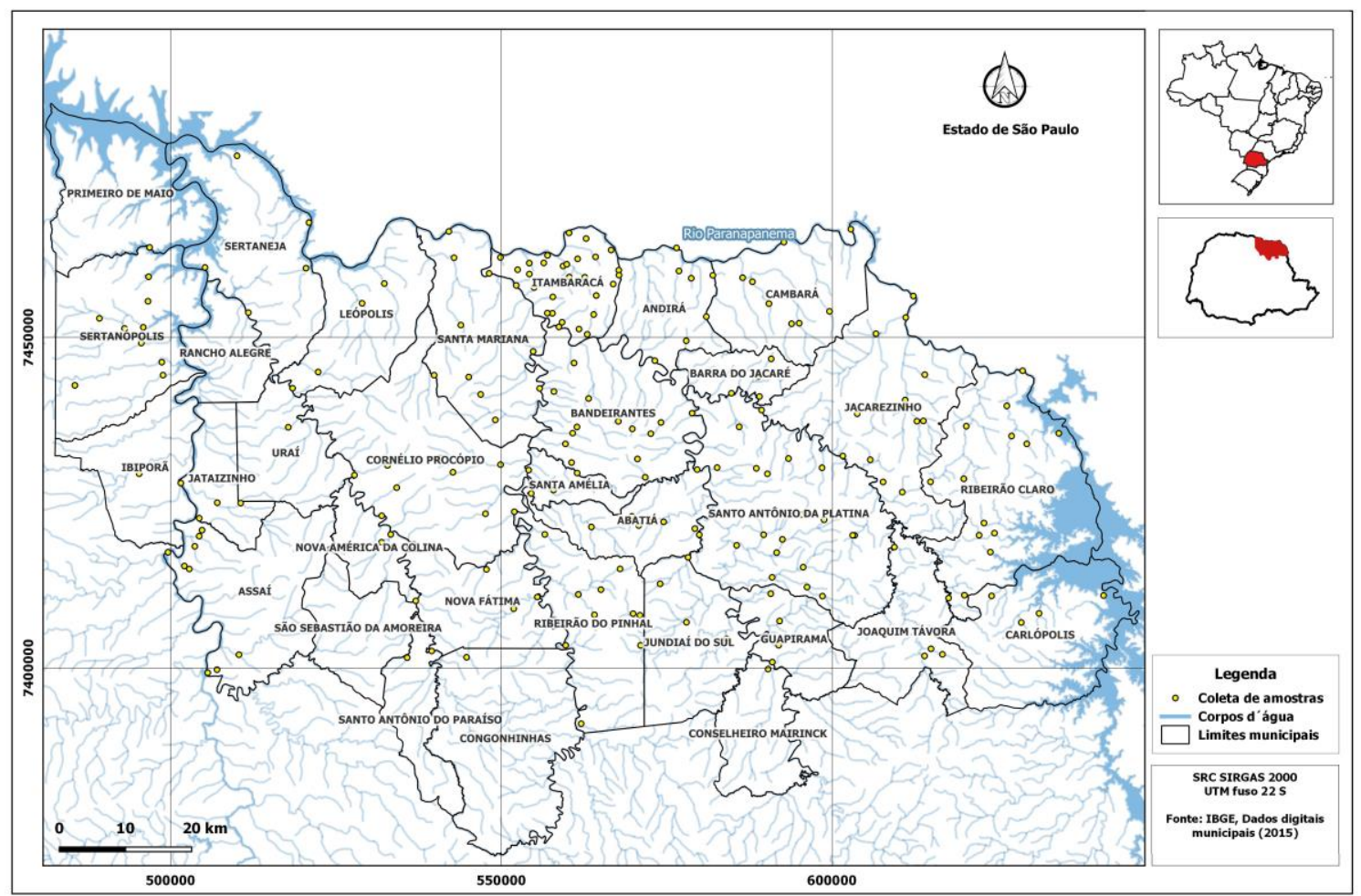

Fonte - Modificado de GOLONO de DEUS (2016) e dados do presente artigo. 
$\mathrm{Na}$ fase analítica foram utilizados um potenciômetro com sensibilidade para $0,1 \mathrm{mV}$, eletrodo específico para íon flúor, soluções padrão de íon flúor para a curva de calibração nos valores 0,125 ; 0,$25 ; 0,5 ; 1,0$ e $2,0 \mathrm{mg} / \mathrm{L}$ de Flúor. A solução TISAB II preparada foi adicionada às amostras, para estabilizar o pH e garantir que todo o íon flúor esteja livre na solução, bem como o uso de água deionizada para limpeza do eletrodo entre as análises.

Os teores obtidos foram sumarizados na forma de mapas georreferenciados a partir da utilização do software livre QGis 2.18, por meio do método de interpolação Natural Neiborhood (FERREIRA, 2014).

\section{DISCUSSÃO E RESULTADOS INGESTÃO DE FLÚOR E RELAÇÕES COM A SAÚDE HUMANA}

O flúor é apontado como um elemento essencial para a saúde humana (OMS, 2002, tendo em vista que a ingestão de teores controlados deste elemento químico promove o endurecimento da matriz mineral dos dentes e do esqueleto, prevenindo a ocorrência de cárie dentária (CURY, 1992; PIRES, 2008).

$\mathrm{Na}$ contramão dos benefícios associados, se consumido em excesso, o flúor pode apresentar toxicidade aguda ou crônica ao organismo humano. A toxicidade aguda ocorre pelo consumo de alta concentração de flúor acima de $5 \mathrm{mg} \mathrm{F}$-/Kg em uma única dose, o que pode ocasionar náuseas alguns minutos após a ingestão e parada cardíaca, desorientação e óbito apenas após algumas horas. Se considera que a toxicidade crônica é resultado da ingestão de flúor em concentrações acima do limite adequado por período prolongado, o que pode ocasionar disfunções e até mesmo desenvolver patologias (PINESE e MARTINS JUNIOR, 2005; FUNASA, 2012).

A toxicidade do flúor tem sido apresentada de modo recorrente em diversos trabalhos científicos, mostrando que a ingestão de teores inadequados, de acordo com os parâmetros estabelecidos, tem apresentado estreita relação com prejuízos à saúde humana. Diversos estudos têm apontado a ocorrência de sinais clínicos adversos associados à ingestão de teores elevados flúor (CANGUSSU et al., 2002; SILVA et al., 2006).

No Brasil, conforme anteriormente antecipado, o valor máximo de concentração a ser praticado nos sistemas de abastecimento público ou privado, obedece a última legislação do MS que é a Portaria Complementar no5 (BRASIL, 2017), que admite o teor de até $1,5 \mathrm{mg} / \mathrm{L}$ de íons de fluoreto. Por outro lado, tanto na esfera nacional como na estadual (e.g. Paraná) não há uma legislação que traga a obrigatoriedade para um valor mínimo de concentração de fluoretos. Adicionalmente, todo o setor empresarial envolvido com águas de abastecimento, incluindo aqueles de envase em vasilhames plásticos para comercialização como água mineral, não se atêm com o devido rigor à legislação.

A fluorose dentária é uma patologia decorrente da toxicidade associada à ingestão prolongada de concentrações elevadas de flúor, contudo, outros fatores podem influenciar o grau de severidade da patologia. Segundo Cury (2001) o consumo de flúor em jejum aumenta para 100\% a absorção deste elemento pelo organismo, podendo ocasionar distúrbios metabólicos e alterações de atividades renais, que acompanhados com a deficiência nutricional (baixo cálcio, baixa vitamina $\mathrm{C}$ e o baixo peso corporal) podem acentuar o grau de severidade da fluorose dentária.

Conforme Dissanayake e Chandrajith (2009) crianças com idade inferior a sete anos são particularmente mais suscetíveis à fluorose dentária, visto que neste período está ocorrendo a formação e calcificação dos dentes permanentes. É nesta faixa etária que se tem uma tendência à prescrição de medicamentos pediátricos, que segundo Anzai (2003), contêm na sua composição concentrações elevadas de flúor, mas sem haver na bula uma descrição clara da finalidade deste elemento.

Em relação aos sintomas clínicos que possibilitam o diagnóstico da fluorose dentária ressalta-se que estes na fase inicial da patologia se dão principalmente por sinais aparentes nos esmaltes dos dentes e prejudicam, sobretudo, a estética. Estes sinais são comumente expressos por alterações na coloração, variando desde uma tonalidade esbranquiçada até manchas ou linhas opacas.

$\mathrm{Na}$ Figura 2 se verifica que nos casos mais graves ocorrem manchas mais escuras, e além de prejudicarem a estética, também podem causar danos à estrutura dentária, dores, dificuldades de mastigação e até mesmo a perda dos dentes. $\mathrm{Na}$ avaliação pelos profissionais da Saúde Bucal tem 
sido muito utilizado o Índice de Dean (1942). Em alguns casos, contraditoriamente a fluorose dentária pode acarretar a proliferação de cáries (CANGUSSU et al., 2002).

Pesquisadores como Frazão, Peres e Cury (2011), apontam que nos casos mais leves a fluorose dentária não é considerada um prejuízo para a qualidade de vida, e em decorrência da prevalência de cárie dentária antes da fluoretação das águas de consumo público, a fluorose foi considerada um preço a ser pago pelo benefício da prevenção de cáries.

O diagnóstico precoce é o melhor meio de corrigir os danos estéticos e estruturais causados pela fluorose dentária, pois esta é uma patologia de caráter permanente. Embora não tenha cura, pode ser amenizada com tratamentos corretivos e de restauração, que segundo Velásquez et al. (2006) consiste basicamente em lixamento do esmalte poroso até a remoção das manchas. Contudo, em casos mais graves este tratamento não é eficaz, sendo necessário implante de coroas e facetas dentárias.

Segundo informações da OMS (1969) o flúor funciona como uma toxina cumulativa no organismo e é raramente encontrado no sangue, pois em sua maioria é eliminado pela urina e o restante é absorvido pelo tecido ósseo. Tal constatação assevera a relação entre o consumo de flúor em doses elevadas e os possíveis prejuízos ao tecido ósseo. Andreazzini, Figueiredo e Licht (2006) apontam que o consumo de quantidades muito elevadas de fluoretos durante um período longo e continuado de tempo, pode estimular a proliferação de osteoblastos desenvolvendo o endurecimento anormal da densidade óssea, a saber fluorose esquelética e/ou óssea.

Figura 2 - Sintomas aparentes da fluorose dentária, conforme o grau de severidade proposto por Dean (1942).

NORMAL

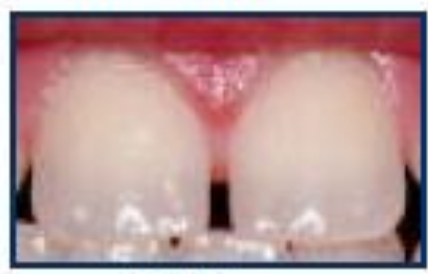

LEVE

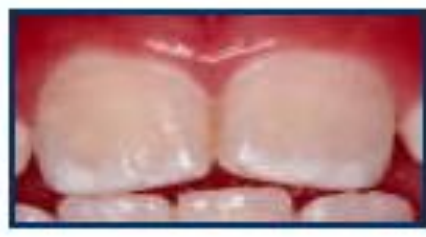

QUESTIONÁVEL

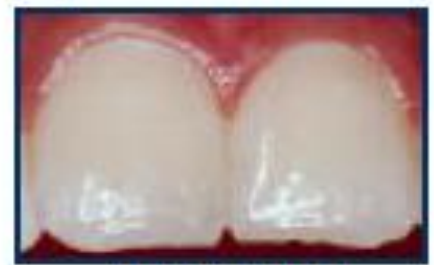

MODERADA

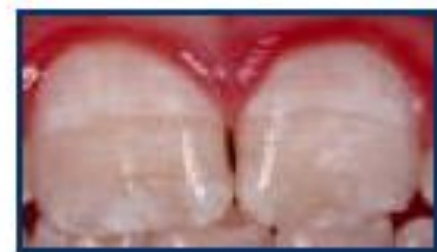

MUITO LEVE

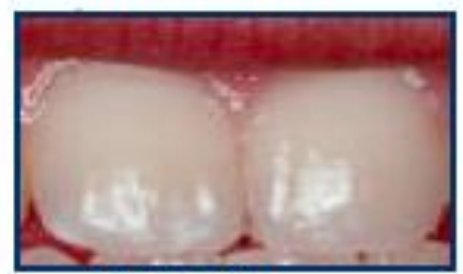

SEVERA

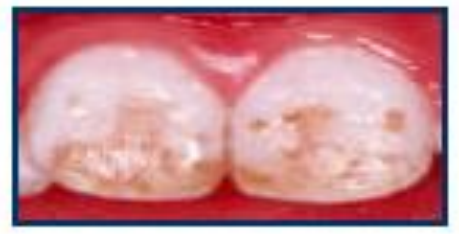

Fonte - Modificado de DISSANAYAKE e CHANDRAJITH, (2009).

Assim como no caso da ocorrência de fluorose dentária, além de uma alta ingestão de flúor por meio da água, outros fatores associados podem ser responsáveis pelo desenvolvimento da fluorose esquelética e/ou óssea, como a desnutrição, o clima e a ingestão por outras fontes, como os alimentos (OMS, 2002).

O quadro clínico da fluorose óssea varia desde dores nas costas, no pescoço, podendo até causar deformações irreversíveis nos ossos, como a calcificação dos ligamentos e a hiper densidade óssea. Em alguns casos mais graves a fluorose óssea acarreta invalidez e até mesmo a morte (REDDY; RAO; SARADA, 1969; GUIMARÃES, 2001).

Por ser resultado de um processo prolongado de acúmulo de flúor nos ossos, a fluorose esquelética e/ou óssea ocorre principalmente em indivíduos na faixa etária entre trinta a cinquenta anos. Contudo, com a ingestão de teores muito elevados de flúor e por um longo período é possível que haja sinais de toxicidade nos ossos em indivíduos de faixas etárias mais jovens, incluindo crianças (DISSANAYAKE e CHANDRAJITH, 2009). 
Afora a fluorose dentária e óssea, outras patologias e disfunções vêm sendo associadas à toxicidade do flúor no organismo humano, entre elas Diesendorf e Sutton (1986) incluem as erupções cutâneas, dores de cabeça, distúrbios gástricos, feridas na boca e redução temporária da capacidade urinária. Outras patologias, como câncer, problemas respiratórios, hepatites e doenças renais têm sido apontadas por alguns pesquisadores e especialistas, contudo não se tem nenhuma correlação científica (DISSANAYAKE e CHANDRAJITH, 2009).

Algumas relações entre flúor e câncer, têm sido apontadas valendo-se de afirmativas pautadas em resultados, de que em áreas fluoretadas dos Estados Unidos as taxas de câncer ósseo entre indivíduos na faixa etária de nove a dezenove anos é cerca de sete vezes maior do que as áreas em que não há fluoretação (GATRELL e ELLIOTT, 2009). Conforme Colquhoun (1997), estudos realizados na China, indicam que as crianças acometidas pela fluorose dentária possuem dificuldades de aprendizagem e diminuição do Quociente de Inteligência - QI.

Muito embora somente a fluorose dentária e óssea sejam patologias comprovadamente relacionadas à ingestão de flúor, é preciso que o consumo deste elemento químico seja equilibrado, levando em consideração as diversas fontes de ingestão - que pode ocorrer pelo uso de medicamentos pediátricos, pela ingestão de produtos fluoretados - cremes e enxaguatórios bucais, por meio do consumo de alguns alimentos e bebidas - peixes, mariscos, frango, chás, fórmulas infantis e leite (CANGUSSU et al., 2002).

Apesar das evidências de que o consumo prolongado de teores irregulares de fluoreto pode causar malefícios à saúde humana, a inserção de flúor em produtos de higiene bucal, bem como no tratamento de águas utilizadas para o abastecimento público, tem sido praticada na intenção de promover melhorias significativas na saúde coletiva (CALDARELLI; LUCAS; SILVA, et al., 2016).

\section{APONTAMENTOS SOBRE A FLUORETAÇÃO DAS ÁGUAS DE CONSUMO}

Tendo em vista as evidências de que o consumo prolongado de teores elevados de flúor pode apresentar toxicidade ao organismo humano é que se tem uma discordância no meio acadêmico e profissional, quanto à limitação do uso de flúor e indispensabilidade da inserção de íons de fluoreto nas águas de abastecimento público, ação denominada de fluoretação controlada.

Sob a ótica de Diesendorf e Sutton (1986) o termo "controlada" não é apropriado, tendo em vista que a dose individual de fluoreto depende não só da concentração na água, mas também da quantidade de líquido ingerido diariamente. Para Connett (2012) é impossível controlar a dose que cada indivíduo consome de flúor, tendo em vista que algumas pessoas como trabalhadores braçais, atletas, diabéticos, por exemplo, devido à profissão ou disfunções orgânicas ingerem maior quantidade de água diariamente.

Embora um grupo considerável de profissionais da saúde bucal defendam a fluoretação para classes sociais mais vulneráveis, outro tem se destacado por pesquisadores que salientam os malefícios associados ao consumo de flúor, como Diesendorf e Sutton (1986) que questionam a relevância do consumo deste elemento por meio da água de abastecimento público. Segundo os autores, em doses elevadas, o flúor é bem conhecido por sua toxicidade para seres humanos e animais, sendo usado inclusive na composição de venenos para ratos.

Em 1938 após estudos de casos, Dean constatou que em cidades onde as águas continham teores de fluoretos naturais acima de $1 \mathrm{mg} / \mathrm{L}$, o número de crianças com cárie dentária era bem menor que em cidades onde os teores de flúor eram mais baixos (FUNASA, 2012). A partir de tal constatação, Dean e outros pesquisadores procuraram incentivar a fluoretação nos EUA (OUTERBRIDGE, 1986) e estabelecer a relação entre o limite mínimo de flúor natural existente na água que não provocasse danos ao esmalte dentário e fosse efetivo na prevenção de cárie dentária (BUENDIA, 1996).

Embora pesquisas na década de 1950 tenham verificado redução de cáries onde o consumo de água apresentava teores de flúor entre 0,2-0,9 mg/L (GATRELL e ELLIOTT, 2009), muitas críticas foram imputadas à metodologia adotada, no que concerne principalmente às comunidades escolhidas para os primeiros testes, bem como por ter havido omissão de dados contraditórios (STEFANO, 1954; SUTTON, 1986; ZIEGELBECKER, 1970). 
Em 1958 a OMS instituiu um Comitê de Peritos em fluoretação da água, que logo no primeiro relatório deu parecer favorável à fluoretação, indicando-a como uma medida de saúde pública. Em 1975 na XXV Assembleia Mundial da Saúde a OMS desenvolveu um programa para a promoção da fluoretação de água de abastecimento de comunidades, enfatizando a importância de se utilizar o flúor nas concentrações adequadas na água de abastecimento (VIEGAS et al., 1987).

Atualmente, a fluoretação de águas de abastecimento público, embora alvo de muitas críticas, tem sido uma prática recorrente em diversos países. Contudo, segundo Connett (2012) na maioria dos países desenvolvidos, incluindo o Japão e em $97 \%$ da população da Europa Ocidental, a fluoretação das águas de consumo foi abolida e/ou nem sequer implementada. Parte desses países optaram pela aplicação de creme e enxaguantes bucais (CALDARELLI; LUCAS; SILVA,-et al., 2016).

Como se observa na Figura 3, os casos de cárie dentária têm diminuído em países que praticam a fluoretação de águas de abastecimento público (Nova Zelândia, Estados Unidos, Austrália, Irlanda), bem como nos países em que não adotaram essa prática (Islândia, Itália, Japão, Bélgica). Para Connett (2012) a escovação dos dentes é por si só eficaz na prevenção de cáries dentais, e isso explicaria a redução da ocorrência de cáries nos dois grupos de países.

Por outro lado no Brasil, diferentes pesquisadores da área de saúde bucal, entre eles Cury (2001) e Cury et al. (2019), consideram que a água fluoretada é um método de uso coletivo com um forte impacto em reduzir os níveis de cárie na população, sobretudo de baixa renda, cuja eficiência foi comprovada em dezenas de países através de centenas de avaliações.

Figura 3 - Evolução histórica dos casos de cárie dentária em países com ou sem fluoretação nas águas de abastecimento público.

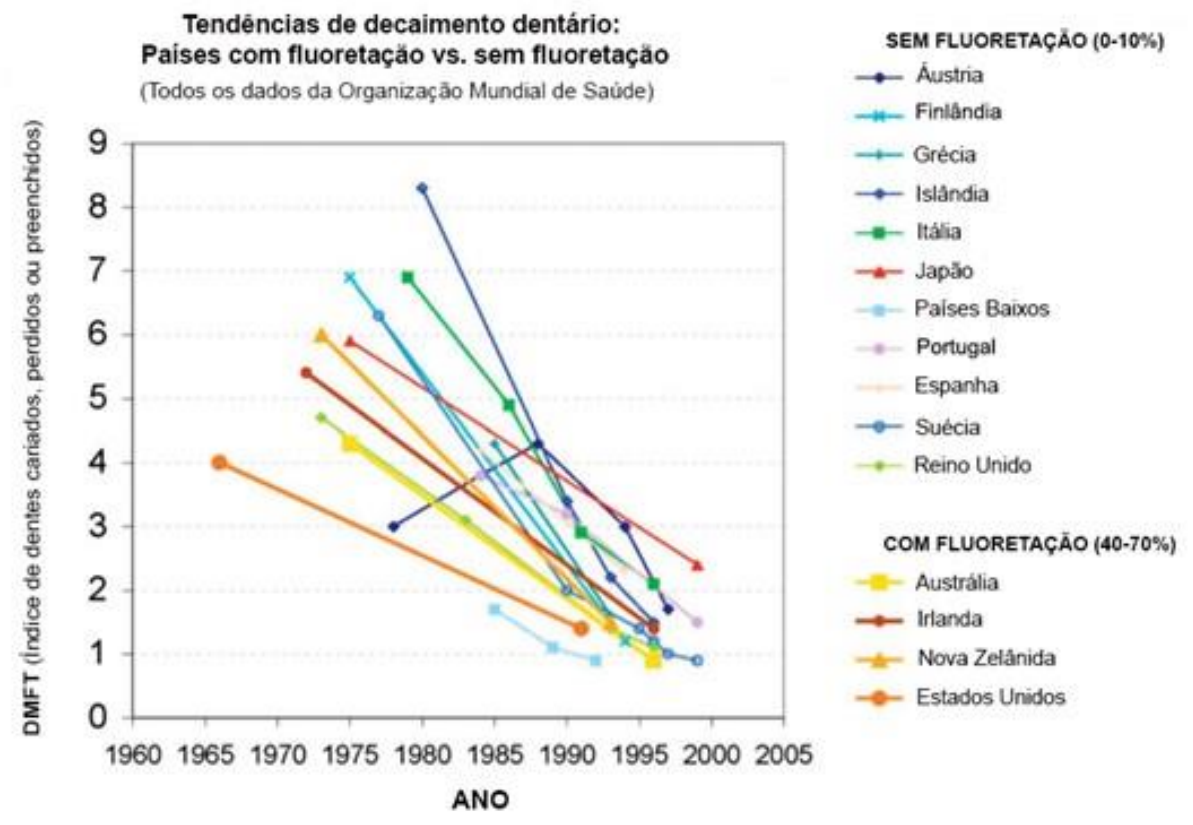

Fonte - Modificado de Connett (2012).

\section{PARÂMETROS ADOTADOS E LEGISLAÇÃO ACERCA DO FLÚOR EM ÁGUAS DE CONSUMO}

Visando estabelecer os teores mínimos de flúor nas águas, que previnam a ocorrência de cáries, e máximos, que não sejam passíveis de causar danos à saúde, é que se têm atualmente parâmetros definidos por órgãos supranacionais e adaptações nacionais.

A OMS (1984) definiu em $0,79 \mathrm{mg} / \mathrm{L}$ o teor de flúor considerado como ideal na água potável para países tropicais e para países de clima frio teores de até $1,4 \mathrm{mg} / \mathrm{L}$. Tal especificação de parâmetros, com base em zonas climáticas, é estabelecida considerando que a quantidade de flúor presente no 
organismo é condicionada, dentre outros fatores, pela quantidade total de água ingerida diariamente, o que está diretamente relacionado com as condições climáticas locais (OMS, 1969).

Os parâmetros estabelecidos pela OMS (1984) são amplamente utilizados em termos globais, aliados às adaptações realizadas por órgãos nacionais. No Brasil, as diferenciações climáticas estabelecidas pela OMS foram adotadas e adaptadas às condições do país. A fluoretação das águas de consumo é obrigatória no Brasil desde 1974, de acordo com a Lei Federal 6.050 (BRASIL, 1975). Um ano mais tarde a Portaria 635 (BRASIL, 1976) estabeleceu os padrões e normas para a fluoretação e atualmente cerca de metade da população do país tem acesso à água fluoretada (FRAZÃO; PERES; CURY, 2011).

As Portarias 2.914 e 5 do Ministério da Saúde (BRASIL, 2011; 2017 respectivamente) estabeleceram os parâmetros legislativos mais recentes acerca dos teores permitidos de elementos químicos nas águas de consumo e da fluoretação no Brasil. Em relação ao flúor nestes documentos, se determina como máximo permitido concentrações de até $1,5 \mathrm{mg} / \mathrm{L}$ ou $\mathrm{ppm}$, contudo, nos parágrafos concernentes ao padrão de potabilidade, se preconiza que os valores recomendados para concentração de íon fluoreto devem observar a Portaria no 635/GM/MS, de 30 de janeiro de 1976 (BRASIL, 1976). Nela se orientam posturas que geralmente são negligenciadas no Brasil, onde se registra uma diferenciação dos parâmetros de consumo de flúor, que obedece a diferenciação das temperaturas observadas no âmbito do território brasileiro, ou seja, com as médias das temperaturas máximas diárias do ar, conforme pode ser observado na Tabela 1.

Visando definir os parâmetros de concentração de flúor a serem adotados na presente pesquisa, buscaram-se informações das médias históricas das temperaturas máximas diárias do ar na área investigada. Contudo, somente quatro municípios analisados, a saber: Cambará, Bandeirantes, Ibiporã e Joaquim Távora, apresentam levantamentos históricos necessários e estações meteorológicas do Instituto Agronômico do Paraná (IAPAR, 2013), um dos principais órgãos de monitoramento climatológico do estado.

Considerando a proximidade entre os municípios analisados e a pequena diferenciação latitudinal, os dados disponíveis acerca das médias das temperaturas máximas dos municípios mencionados serão adotados para estabelecer os parâmetros de concentrações de flúor em águas de consumo público para toda a região nordeste do Paraná.

Tabela 1 - Limites de flúor para as águas de consumo, de acordo com as médias das temperaturas máximas diárias.

\begin{tabular}{c|c|c|c}
\hline \multirow{2}{*}{$\begin{array}{c}\text { Médias das temperaturas } \\
\text { máximas diárias do } \mathrm{ar} \mathrm{em}^{\circ} \mathrm{C}\end{array}$} & \multicolumn{3}{|c}{$\begin{array}{c}\text { Limites recomendados para a } \\
\text { concentração de íons de fluoreto em } \\
\mathrm{mg} / \mathrm{L}\end{array}$} \\
\cline { 2 - 4 } & Mínimo & Máximo & Ótimo \\
\hline $10,0-12,1$ & 0,9 & 1,5 & 1,2 \\
\hline $12,2-14,6$ & 0,8 & 1,5 & 1,1 \\
\hline $14,7-17,7$ & 0,8 & 1,3 & 1,0 \\
\hline $17,8-21,4$ & 0,7 & 1,2 & 0,9 \\
\hline $21,5-26,3$ & 0,7 & 1,0 & 0,8 \\
\hline $26,4-32,5$ & 0,6 & 0,8 & 0,6 \\
\hline
\end{tabular}

Fonte - Ministério da Saúde (BRASIL, 1976). Org.: os autores.

Como se observa no Quadro 1, as médias das temperaturas máximas dos municípios analisados são superiores a $27^{\circ} \mathrm{C}$. Portanto, em concordância com os critérios estabelecidos pelo Ministério da

$\begin{array}{lllll}\text { Caminhos de Geografia } \quad \text { Uberlândia-MG } & \text { v. 22, n. } 81 \quad \text { jun./2021 } & \text { p. 88-105 } & \text { Página } 95\end{array}$


Saúde (BRASIL, 1976), as concentrações de flúor admitidas para as águas de consumo público nos municípios abordados nesta pesquisa, devem variar de um mínimo de $0,6 \mathrm{mg} / \mathrm{L}$ para um máximo de 0,8 mg/L, sendo este último denominado Valor Máximo Recomendável (VMR).

Quadro 1 - Média das temperaturas máximas da área investigada.

\begin{tabular}{|c|c|}
\hline Municípios & $\begin{array}{c}\text { Média das temperaturas } \\
\text { máximas }\end{array}$ \\
\hline Cambará & $28,7 \mathrm{C}$ \\
\hline Joaquim Távora & $28,0 \mathrm{C}$ \\
\hline Bandeirantes & $28,7 \mathrm{C}$ \\
\hline Ibiporã & $27,9 \mathrm{C}$ \\
\hline \multicolumn{2}{|c|}{ Fonte - IAPAR, 2013. } \\
\hline
\end{tabular}

Tal intervalo também se encontra delineado em Pinese et al. (2017) e Pinese, Ross e Alves (2019), sendo considerado como ideal para a saúde bucal, onde valores inferiores a 0,6 $\mathrm{mg} / \mathrm{L}$ sugerem um maior risco de gerar cáries, enquanto os maiores que $0,8 \mathrm{mg} / \mathrm{L}$ ampliam o risco para fluorose dentária. Assim, o intervalo entre 0,6 e $0,8 \mathrm{mg} / \mathrm{L}$ de teores de flúor em água de consumo humano, são tidos como apropriados tanto para evitar cáries como a fluorose dentária.

\section{GEOLOGIA E CONCENTRAÇÕES DE FLÚOR NO NORDESTE DO PARANÁ E ÁREAS DE RISCO}

O contexto geológico da região se insere na Bacia Sedimentar do Paraná (ALMEIDA et al., 2000), configurada como uma depressão que comporta pacotes de rochas ígneas e sedimentares (PINESE, 2002; MILANI et al., 2007).

$\mathrm{Na}$ área investigada se evidencia o predomínio de rochas ígneas vulcânicas da Formação Serra Geral (MARTINS; WILDNER; HARTMANN, 2011), atualmente elevada à categoria de Grupo (LICHT e ARIOLI, 2018), e em menor ocorrência as litologias sedimentares das formações Botucatu, Piramboia, Rio do Rastro, Teresina, Serra Alta, Irati e Palermo (Figura 4), dentre outras (ROSA FILHO et al., 2011).

A Formação Serra Geral representa um processo vulcânico ocorrido entre o Triássico superior e o Cretáceo superior, de característica fissural intracratônica e que recobre cerca de $75 \%$ da Bacia Sedimentar do Paraná (ALMEIDA et al., 2000). Está associado à ruptura do Gondwana quando ainda perduravam condições desérticas de sedimentação da Formação Botucatu (ALMEIDA et al., 2000).

Em geral, se apresentam como derrames de basaltos e andesi-basaltos toleíticos (PICCIRILLO et al., 1988), em pacotes fortemente fraturados com famílias se orientando desde posições verticaissubverticais até horizontais.

Esta feição primária, aliada a ação tectônica posterior, confere ao conjunto alto grau de porosidade e permeabilidade. Consequentemente, se torna o melhor caminho para fontes naturais de flúor advindas de exalações e vapores ácidos na forma de gases magmáticos, depósitos hidrotermais, obsidianas e minerais (MARIMON, 2006; LICHT e ARIOLI, 2018), os quais são lixiviados próximo ou na superfície.

Subjacente à Formação Serra Geral se encontra os arenitos das formações Botucatu e Pirambóia, marcando os limites das cuestas (escarpa mesozóica) de borda da Bacia Sedimentar do Paraná (MAACK, 2002). Também, todas as demais litologias regionais de menor expressão (Figura 4), se encontram subjacentes aos estratos anteriormente mencionados.

Interessante notar, que o alinhamento do contato litológico (Figura 4) entre as vulcânicas e os sedimentos apresenta direção aproximada N55-60 $\mathrm{E}$ (SW-NE), muito semelhante ao alinhamento dos picos dos teores de fluoretos na região (veja considerações finais). 
Conforme antecipado, alguns estudos em escala regional em levantamentos de baixa densidade, têm demonstrado que a região nordeste do Paraná apresenta níveis irregulares de flúor nos solos e nos recursos hídricos (Figuras 1 e 5). De acordo com Licht (2006) na região investigada existe uma área flúor-anômala de aproximadamente $10.000 \mathrm{~km}^{2}$, abrangendo 47 municípios e uma população de 700.000 habitantes (Figura 5). Nesta área os teores de flúor são elevados tanto em águas superficiais $(0,9 \mathrm{mg} / \mathrm{L})$, quanto nos recursos hídricos subterrâneos onde foram identificadas concentrações de flúor de até $2,2 \mathrm{mg} / \mathrm{L}$.

As concentrações elevadas de flúor identificadas são decorrentes da própria estrutura geológica da região, contudo as empresas de saneamento responsáveis pelo abastecimento público realizam fluoretação, aumentando consideravelmente os teores de flúor nas águas de consumo. A fluoretação das águas de abastecimento público, foi adotada no Estado do Paraná em 1958 na cidade de Curitiba (primeira capital brasileira a receber o benefício) e atualmente a população urbana de 390 municípios tem acesso à água fluoretada (PARANÁ, 2013). No estado foram adotados ainda outros programas voltados a evitar a ocorrência de cárie dentária - Programa Estadual de Bochecho com Flúor e Escovação Dental Supervisionada, implantados em 1980, que atingem atualmente 750 mil escolares (PARANÁ, 2013).

Considerando a estreita relação entre o consumo de teores elevados de flúor e sinais de toxicidade ao organismo humano, se evidencia a possibilidade de ocorrência de patologias em função do consumo prolongado de flúor na área investigada. De acordo com Pires (2008), no município de Itambaracá, localizado no norte paranaense, por meio estudos hidrogeoquímicos foram identificadas concentrações de flúor de até $1,79 \mathrm{mg} / \mathrm{L}$ em recursos hídricos subterrâneos in natura, os quais são utilizados para o consumo da população local. Estudos epidemiológicos realizados neste município por Morita et al. (1998), Cardoso (2002) e Pinese et al. (2002) constataram a prevalência de fluorose dentária em $72 \%$ de crianças em idade escolar, sendo $61 \%$ considerados casos de gravidade severa conforme o Índice de Dean (Figura 2).

Figura 4 - Nordeste do Paraná: Contexto Geológico regional indicando predomínio territorial de rochas vulcânicas da Formação Serra Geral, com limite de cobertura e contato litológico orientado SW-NE.

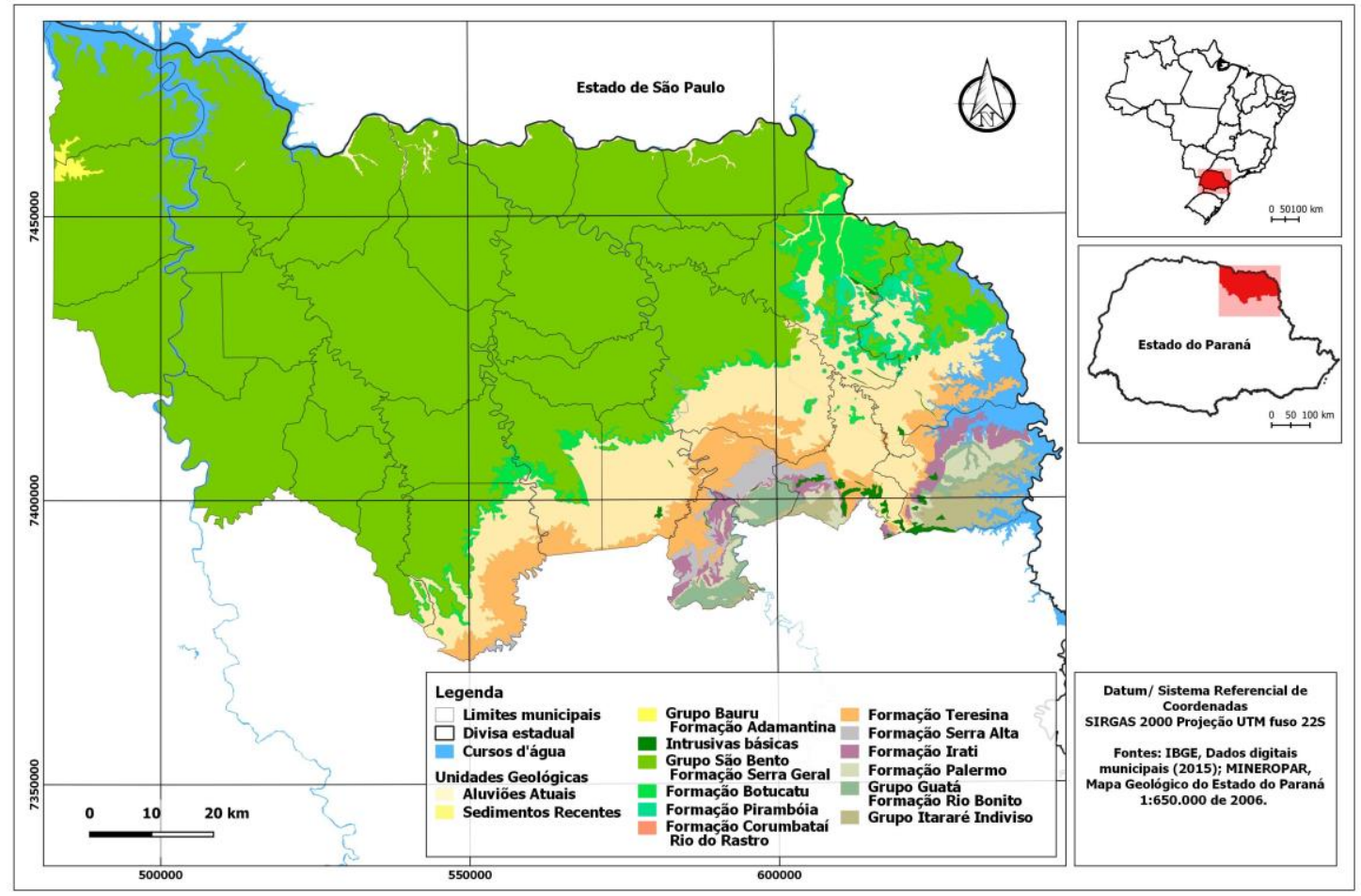

Fonte - Modificado de Golono de Deus (2016) e presente artigo. 
Figura 5 - Estado do Paraná: Dimensão da anomalia dos teores de flúor nas águas superficiais do Nordeste em levantamentos de baixa densidade.

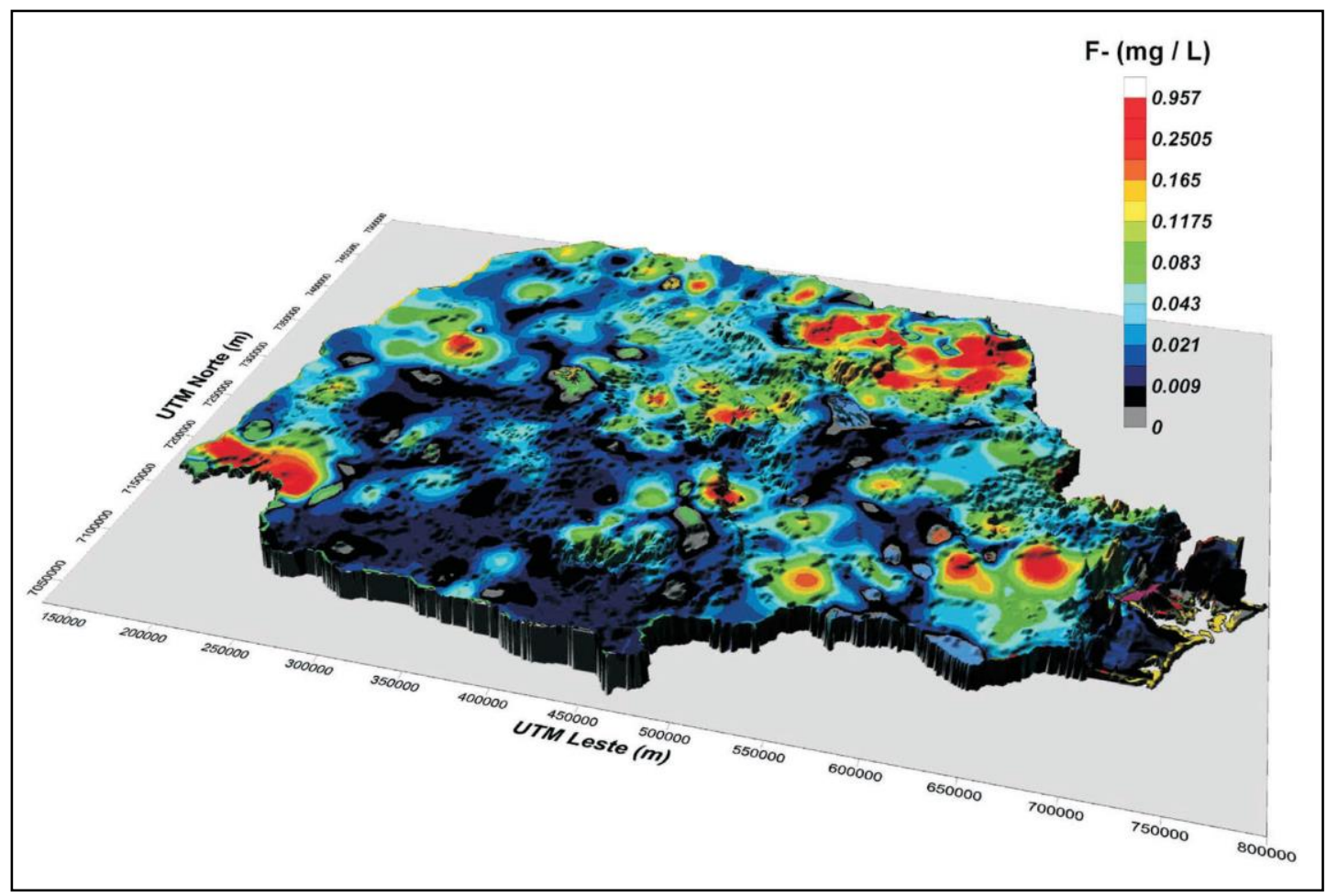

Fonte - Modificado de MINEROPAR, (2001); LICHT (2006).

Os dados dos teores de flúor obtidos em levantamentos de alta densidade nos recursos hídricos in natura, das bacias hidrográficas utilizadas para o abastecimento público no nordeste paranaense se encontram sintetizados no mapa da Figura 6, na qual se observa a distribuição cartográfica destes teores nos hidrossistemas superficiais da região.

$\mathrm{Na}$ Figura 6 se verifica que na área de abrangência da bacia hidrográfica do Baixo Rio Tibagi, próximo ao município de Jundiaí do Sul, são assinalados teores de flúor em desacordo com os parâmetros propostos nesse artigo como ideias a saúde bucal, pois oscilaram de $0,7 \mathrm{mg} / \mathrm{L} \mathrm{a} \mathrm{1,0} \mathrm{mg/L.}$

No município de Santo Antônio da Platina e em Jacarezinho identificaram-se amostras com concentrações de flúor acima de $0,8 \mathrm{mg} / \mathrm{L}$ (Figura 7). Tais amostras, ultrapassam o VMR adotado, a saber: $0,81 \mathrm{mg} / \mathrm{L}, 1,1 \mathrm{mg} / \mathrm{L}$ e $1,2 \mathrm{mg} / \mathrm{L}$.

Não se objetiva no presente trabalho estabelecer uma relação causal, identificando as concentrações de flúor na área de estudo e relacionando de maneira determinística com os efeitos a saúde humana. A partir dos dados analisados, evidencia-se que o flúor está presente em excesso nas águas brutas de consumo em alguns municípios do Nordeste Paranaense, em concentrações acima dos parâmetros estabelecidos nessa investigação, bem como daqueles recomendados pelo Ministério da Saúde (1976) e que podem, aliados a outros fatores, ocasionar fluorose dentária e/ou óssea na população local.

A presente constatação reforça a necessidade de aprofundamento nos estudos hidrogeoquímicos e epidemiológicos nos municípios de Jundiaí do Sul, Santo Antônio da Platina e Jacarezinho, visando ampliar o banco de amostras de águas de consumo público, incluindo os recursos hídricos subterrâneos, e avaliar in situ possíveis áreas de risco que apresentem registros de casos de fluorose dentária por parte da comunidade odontológica local. 
Figura 6 - Nordeste do Paraná: Delimitação com levantamentos de alta densidade das Áreas dos Teores anormais de Flúor e de Risco à saúde em águas superficiais naturais. Destaque para alinhamento dos picos e halos dos teores de Flúor alinhados de SW-NE.

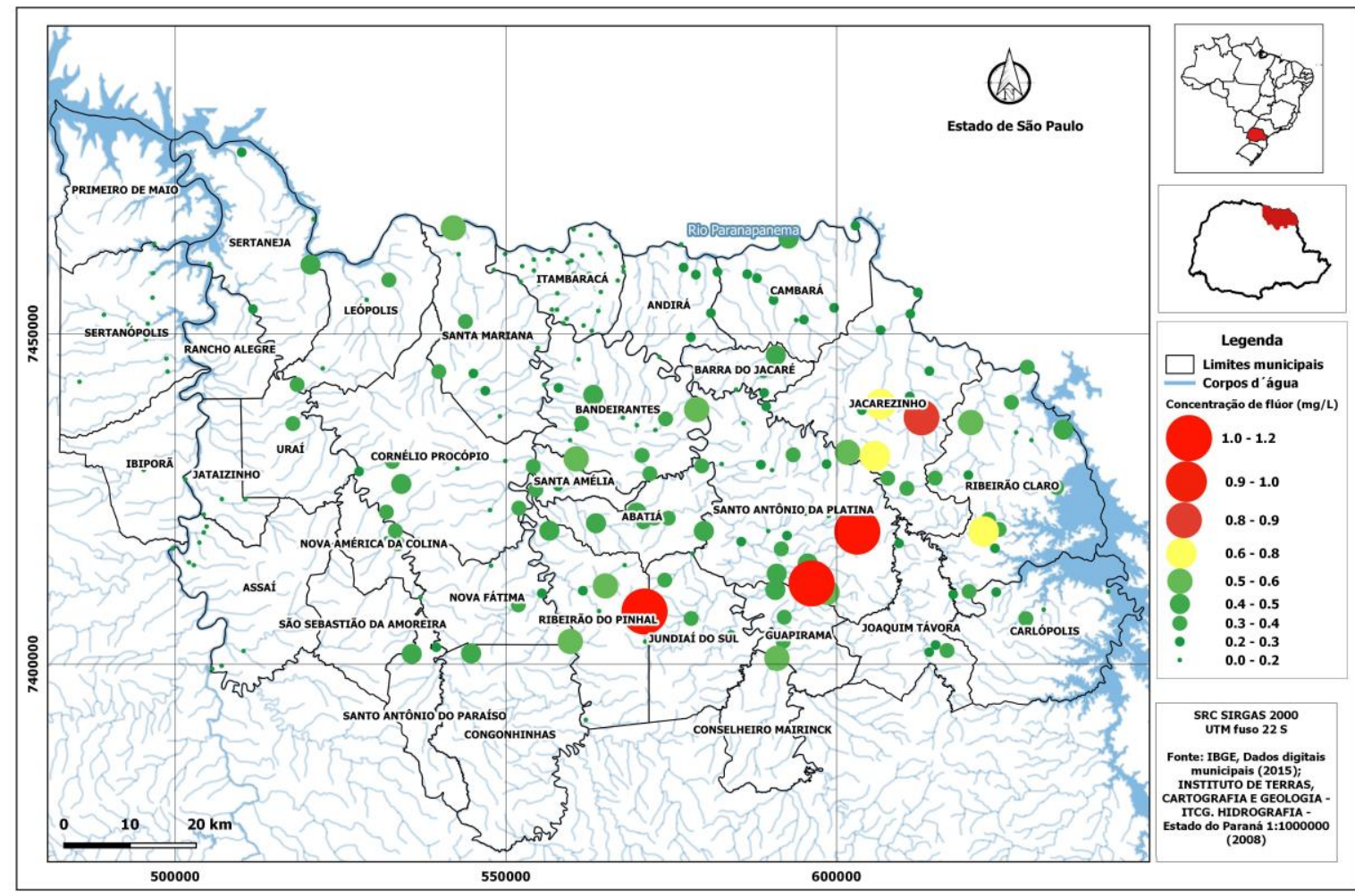

Fonte - Modificado de ITCG-IAT (2006-2008), GOLONO de DEUS (2016) e presente artigo.

Figura 7 - Concentrações de flúor nas amostras de águas superficiais brutas, obtidas em Santo Antônio da Platina e Jacarézinho, bem como intervalo com máximo e mínimo recomendáveis.

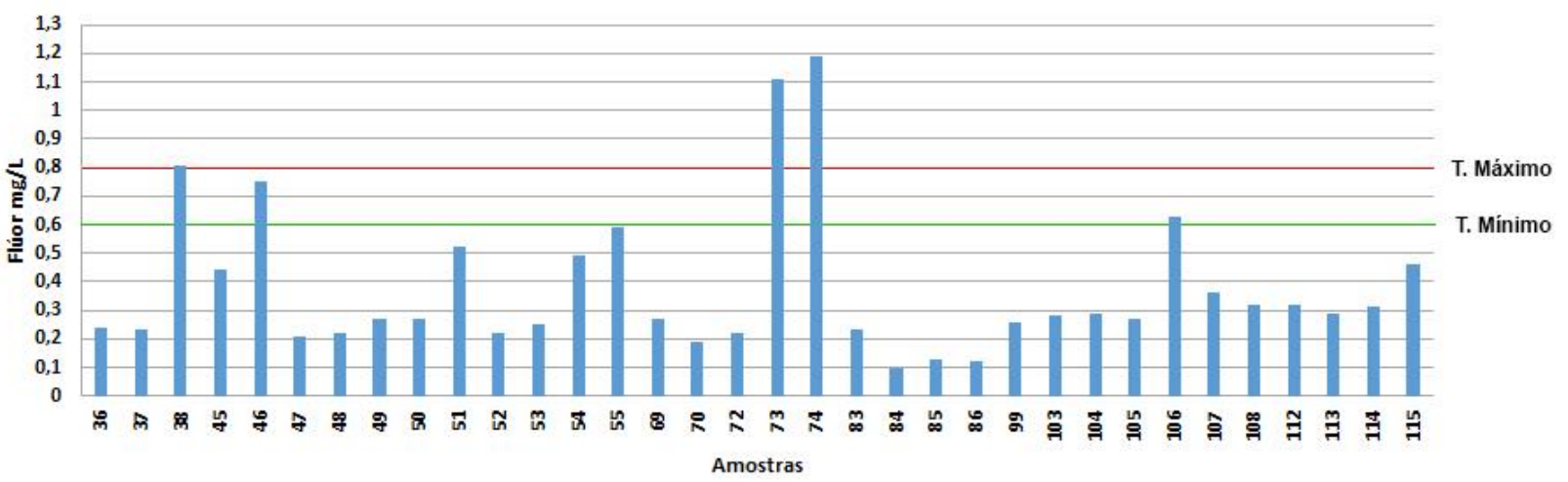

Fonte - Presente artigo.

Nas Regionais de Saúde ou mesmo nos hospitais e postos de saúdes que possuem atendimento odontológico é muito difícil obter informações sobre a ocorrência da fluorose, o que está estritamente associado à dificuldade de um diagnóstico preciso. A fluorose dentária ainda é uma patologia desconhecida por muitas pessoas, em muitos casos por indivíduos acometidos pela doença, ou mesmo pelos próprios profissionais da área de saúde.

No banco de dados do DATASUS não há uma categoria específica referente à fluorose dentária (BRASIL, 2012), contudo, essa patologia pode estar inclusa na categoria: 'transtornos nos dentes e 
nas estruturas de suporte', em decorrência da antecipada dificuldade do diagnóstico preciso. Na área de estudo foram registrados 33 casos de transtornos dentais, sendo sete em Santo Antônio da Platina, onde se constatou concentrações elevadas de flúor; e quatorze nos municípios de Cornélio Procópio, Ribeirão Claro e Joaquim Távora, municípios localizados muito próximos das áreas em que os teores de flúor estão acima de $0,8 \mathrm{mg} / \mathrm{L}$. Infelizmente, a fluorose não é ainda considerada um agravo ou problema de saúde pública, nem mesmo uma doença. Por essa razão, a classe dos odontólogos não a notifica em coletas de dados contínuos e sistematizados como DATASUS. A não alimentação dessa condição, aponta para um dos alertas deste artigo, que indica a necessidade do aprimoramento dos levantamentos epidemiológicos locais específicos nos municípios, comunidades e micros regiões. Este fato, não propiciou a espacialização desejada com a integração da específica patologia com os teores excessivos de flúor obtidos.

O risco corresponde à probabilidade temporal e espacial de acontecimentos de um processo potencialmente perigoso e à expectativa de consequências prejudiciais nas pessoas e nos seus bens, bem como no ambiente, na economia, na sociedade e nos territórios em que se pode manifestar (DAUPHINÉ, 2001; REBELO, 2001; 2010; JULIÃO et al., 2009; CUNHA, 2013). Assim, se pode considerar que a faixa ocupada pelos municípios de Jundiaí do Sul, Santo Antônio da Platina e Jacarezinho apresenta um elevado risco de saúde bucal, tendo em consideração os elevados teores naturais das águas em flúor e o modo como estes valores são ignorados pelas políticas públicas de abastecimento.

Este risco diz respeito tanto ao processo perigoso, potencialmente gerador de doenças, como também à exposição e vulnerabilidade socioambiental das populações (FREITAS e CUNHA, 2012; 2013), particularmente das famílias com crianças e jovens que, como foi dito, muitas vezes não têm percepção dos perigos a que estão sujeitas.

\section{CONSIDERAÇÕES FINAIS}

O flúor, constituinte natural do ambiente e presente em concentrações variáveis nos recursos hídricos, passou a ser inserido nas águas de abastecimento público tendo como embasamento a premissa de que o consumo deficiente de flúor causa maior exposição dos dentes à ocorrência de cáries, muito embora os cremes e enxaguantes bucais, que atualmente são de amplo acesso, tenham desempenhado esta função protetora.

A fluorose dentária considerada como um preço a ser pago pela redução dos casos de cáries, tem se tornado um problema relevante e, mesmo, um importante risco de saúde pública, tendo em vista que tanto na sua forma moderada ou severa ocasiona alterações funcionais e estéticas, que podem interferir negativamente nas diferentes fases do desenvolvimento humano do indivíduo. Entre outros aspectos, os prejuízos à saúde bucal da população poderão afetar ainda na juventude a formação da personalidade, sociabilidade e até na inserção futura no mercado de trabalho.

Conforme se observa por meio das informações e dados analisados no presente trabalho, existem na região Nordeste do Paraná teores de flúor acima dos parâmetros estabelecidos pelo Ministério da Saúde (BRASIL, 1976), bem como do intervalo recomendável calculado para essa região (PINESE et al., 2017; PINESE, ROSS, ALVES, 2019 e presente artigo), nas águas superficiais e subterrâneas in natura em decorrência da própria estrutura geológica local. A referida estrutura em grande parte é recoberta pelas rochas vulcânicas básicas (e.g. basaltos) da Formação Serra Geral (PINESE e GUIMARÃES, 2018), litologia essa frequentemente relacionada a teores de flúor acima do VMR (MARIMON, 2006; LICHT, 2018).

Considerando que em todo Estado Paranaense, está em vigência a política de fluoretação das águas de abastecimento público, com inserção de flúor independente daquelas que apresentam concentrações naturais em níveis elevados, se faz necessário um rígido controle das dosagens adicionais (fluoretação) para evitar toxicidade crônica na população e o risco de fluorose.

As investigações demonstraram que existem na região áreas de risco onde a fluorose dentária é endêmica, afetando principalmente crianças em idade escolar. Tendo em vista que a fluorose dentária ainda é uma patologia desconhecida por muitas pessoas, em muitos casos por indivíduos acometidos pela doença, ou mesmo pelos próprios profissionais da área de saúde, é possível que a mesma ainda não tenha sido diagnosticada a contento, prejudicando a obtenção de dados exatos de casos no 
Estado.

Nas análises das amostras obtidas em bacias hidrográficas da região Nordeste do Paraná, se verificou que nos municípios de Santo Antônio da Platina, Jundiaí do Sul e Jacarezinho existem concentrações de flúor em águas superficiais de abastecimento público, que aliado ao consumo prolongado e ingestão por outras fontes (alimentos, medicamentos, produtos de higiene bucal e outras bebidas), podem ocasionar fluorose dentária na população local.

Sendo assim, se assinala quatro importantes áreas de risco que se alinham aproximadamente na direção SW-NE $\left(\sim N 55-60^{\circ} \mathrm{E}\right)$, evidenciando a necessidade da continuidade dos estudos hidrogeoquímicos e epidemiológicos in situ. Cumpre ressaltar que o referido alinhamento, ocorre através dos picos das áreas de risco com teores máximos de flúor e seus halos de dispersão, os quais se assemelham a um cinturão que coincide com o contato geológico entre os basaltos da Formação Serra Geral e os Arenitos da Formação Botucatu (PINESE et al., 2017).

Provavelmente os fraturamentos horizontais dos maciços basálticos, devem descarregar (nascentes) águas enriquecidas em flúor como fruto da dissolução de fluorapatita e lentes vulcanoclásticas. Se constatada a ocorrência da patologia, há que se alertar as prefeituras municipais e os órgãos gestores quanto a diminuição ou cancelamento do acréscimo de flúor nas águas de abastecimento, como forma de mitigação deste risco de saúde pública.

Por outro lado, é notória (Figura 6) a imensa área de risco com teores em flúor abaixo do recomendável para se evitar a cárie $(\leq 0,6 \mathrm{mg} / \mathrm{L})$, na água bruta superficial do nordeste do Paraná, o que também poderá ser um sério problema na população infanto-juvenil da região.

Enfim, nessa investigação, restou patente que alguns poucos locais dos municípios de Jacarézinho e Ribeirão Claro apresentam águas brutas de abastecimento público sem o excesso, mas também sem insuficiência dos teores de fluoretos indicados como importantes a manutenção da saúde bucal, sendo assim de baixo risco tanto a cárie quanto a fluorose.

\section{AGRADECIMENTOS}

Ao Conselho Nacional de Desenvolvimento Científico e Tecnológico (CNPq), por meio do PSPPG processo 521015/99-5 e CNPq (310.608/2017); bem como a CAPES-FCT (88881.156421/2017-01 e 88887.352716/2019-00) e à Fundação Araucária do Paraná - Processos 19.733 e 41.593, pelo financiamento dos projetos de pesquisa. Também a colaboração científica desenvolvida entre os grupos de pesquisa de Hidrossistemas da Universidade Estadual de Londrina (UEL) e o de Estudos da Natureza e Dinâmicas Ambientais do Centro de Estudos de Geografia e Ordenamento do Território (CEGOT), da Universidade de Coimbra, Portugal.

\section{REFERÊNCIAS}

ALMEIDA, F.F.M.; BRITO NEVES, B.B.; CARNEIRO, C. The origin and evolution of the South American Platform. Earth Sci. Reviews, v. 50. p. 77-111, 2000. https://doi.org/10.1016/S0012$\underline{8252(99) 00072-0}$

ANDREAZZINI, M. J; FIGUEIREDO, B. R; LICHT, O. A. B. Geoquímica do Flúor em águas e sedimentos fluviais da região de Cerro Azul, estado do Paraná: definição de áreas de risco para consumo humano. In: SILVA, C. R; FIGUEIREDO, B. R; CAPITANI, e. M; CUNHA, F. G. (Org.).

Geologia Médica no Brasil: efeitos dos materiais e fatores geológicos na saúde humana e meio ambiente. Rio de Janeiro: CPRM- Serviço Geológico do Brasil, 2006. p. 118- 125.

https://doi.org/10.25249/0375-7536.2006362336346

ANZAI, A. Concentração de flúor em medicamentos pediátricos e risco de fluorose dentária. 2003. Dissertação. (Mestrado em Odontologia) - Universidade de São Paulo, Bauru, 2003.

BRASIL. Decreto no 76.872, de 22 de dezembro de 1975. Regulamenta a Lei oㅜ 6.050, de 24 de maio de 1974, que dispõe sobre a fluoretação da água em sistemas públicos de abastecimento. Diário Oficial da União, 23 dez. 1975; Secção 1. 
BRASIL. Ministério da Saúde. Portaria no 635, de 26 de dezembro de 1975. Aprova as Normas e Padrões sobre a fluoretação da água, tendo em vista a Lei oㅡ 6050/74. Diário Oficial da União, Brasília, 30 jan. 1976. Disponível em: https://goo.gl/FTPHAX. Acesso em: 19 mar. 2019.

. Secretaria de Vigilância em Saúde. Coordenação Geral de Vigilância em Saúde Ambiental. Portaria MS n.o 2.914/2011. Ministério da Saúde, Secretaria de Vigilância em Saúde, Coordenação Geral de Vigilância em Saúde Ambiental. Brasília: Editora do Ministério da Saúde, 2011.

DATASUS, Informações epidemiológicas e morbidade, 2012. Disponível em: <http://tabnet.datasus.gov.br/cgi/deftohtm.exe?sih/cnv/nibr.def>. Acesso em: 19 mar. 2019.

Diretriz nacional do plano de amostragem da vigilância da qualidade da água para consumo humano. Brasília (DF): Ministério da Saúde, 36 p., 2014.

Portaria de Consolidação do Ministério da Saúde no5 de setembro de 2017. Consolidação das normas sobre as ações e os serviços de saúde do Sistema Único de Saúde. Diário Oficial da União, Brasília, Poder Executivo, DF, 28 set. 2017.

BUENDIA, O. C. Fluoretação de águas: manual de orientação prática. São Paulo: American Med, 1996.

CALDARELLI, P. G.; LUCAS, B. B.; SILVA, B. S. Contribuição da água e dentifrício fluoretado na prevalência de cárie e fluorose dentária: uma abordagem baseada em evidências. Revista do Instituto de Ciencias da Saude (UNIP), v. 34, p. 117-122, 2016. Disponível em: https://www.unip.br/presencial/comunicacao/publicacoes/ics/edicoes/2016/02 abrjun/V34 n2 2016 p117a122.pdf. Acesso em: 26 abr. 2019.

CANGUSSU, M. C. T.; NARVAI, P. C.; FERNANDEZ, R. C.; DJEHZIAN, V. A fluorose dentária no Brasil: uma revisão crítica. Caderno Saúde Pública, Rio de Janeiro. v. 18. p. 7-15, Jan-Fev. 2002. https://doi.org/10.1590/S0102-311X2002000100002

CARDOSO, L. M. Fluorose dentária e teores de Flúor na água de Itambaracá- PR. Dissertação (Mestrado em Saúde Coletiva). Universidade Estadual de Londrina, Londrina, 2002.

CECOL - USP - Centro Colaborador do Ministério da Saúde em Vigilância da Saúde Bucal Universidade de São Paulo. Protocolo de Coleta e Análise da Amostra de Água - Projeto Vigifluor. São Paulo, 2014. Disponível em: https://goo.gl/9q3CDg. Acesso em: 01 ago. 2018.

COLQUHOUN, J. Why I changed my mind about water fluoridation. Perspectives in Biology and Medicine. Baltimore, v,41, n.1, 1997. https://doi.org/10.1353/pbm.1997.0017

CONNETT, P. 50 Reasons to Oppose Fluoridation. 2012. Disponível em: <https://goo.gl/gAMkZ5 $>$. Acesso em: 19 mar. 2019.

CUNHA, L. Vulnerabilidade: a face menos visível do estudo dos Riscos Naturais. In: Riscos naturais, antrópicos e mistos. Livro de homenagem ao Professor Doutor Fernando Rebelo, Departamento de Geografia, FLUC, IUC, 2013, pp. 153-165.

CURY, J. A. Flúor dos 8 aos 80? In BOTINNO, M. A.; FELLER, C. (Org.). Atualização na clínica odontológica. São Paulo: Artes Médicas, 1992. p. 375-382

. Uso do flúor e controle de cárie como doença. In: BARATIEI, L. N. et al. (Org.). Odontologia restauradora: Fundamentos e possibilidades. São Paulo: ed. Santos, 2001. p. 32-68.

; RICOMINI-FILHO, A. P.; BERTI, F. L. P.; TABCHOURY, C. P. M. Systemic Effectes (Risks) of Water Fluoridation. Brazilian Dental Journal. 2019. Disponível em http://encurtador.com.br/dgr34. Acesso em: 22 out. 2019.

DAUPHINÉ, A. Risques et catastrophes - Observar, spatializer, comprendre, gérer. Armand Colin, Paris, 2001.

DEAN, H. T. The Investigation of physiological effects by the epidemiological method. In: MOULTON, F.R. (Org.). Fluorine and dental health. Washington, DC: American Association for the Advancement of Science, 1942. p.23-31 
DIESENDORF, M.; SUTTON, P. R. N. Fluoride: New Grounds for Concern. Ecologist, v. 16, n.6, p. 237-246, 1986.

DISSANAYAKE, C.B; CHANDRAJITH, R. Introduction to medical geology: Focus on tropical environments. Berlin: Springer, 2009. https://doi.org/10.1007/978-3-642-00485-8

FERNANDES, J. C. B.; KUBOTA, L. T.; OLIVEIRA NETO, G. Íon-selective electrodes: historical, mechanism of response, selectivity and concept review. Química Nova, v. 24, n. 1, p. 120-130, 2001. https://doi.org/10.1590/S0100-40422001000100020

FERREIRA, M. C. Iniciação à análise geoespacial: teoria, técnicas e exemplos para geoprocessamento. 1.ed. - São Paulo: Editora Unesp, 2014.

FRAZÃO, P.; PERES, M. A.; CURY, J. A. Qualidade da água para consumo humano e concentração de fluoreto. Revista de Saúde Pública, v. 45, n. 5, 2011, p. 964-73. https://doi.org/10.1590/S003489102011005000046

FREITAS, M. I.; CUNHA, L. Modelagem de dados socioambientais visando estudos de vulnerabilidade: o caso de 17 concelhos do centro de Portugal. Revista Geonorte, Edição Especial, V.1, N.4, 2012, p. $816-829$.

Cartografia da vulnerabilidade socio-ambiental. Convergências e divergências a partir de algumas experiências em Portugal e no Brasil”. Urbe, Revista brasileira de gestão urbana, S. Paulo, 5 (1), 2013, pp. 15-31. https://doi.org/10.7213/urbe.7783

FUNASA - Fundação Nacional de Saúde. Manual de fluoretação da água para o consumo humano, Brasília, 2012.

GATRELL, A.; ELLIOTT, S. J. Geographies of health: an introduction. 2 ed. Oxford: Blackwell, 2009.

GOLONO DE DEUS, A. Análise da distribuição espacial dos concentrados de Flúor nas bacias hidrográficas do nordeste paranaense: Relações com a saúde coletiva. Dissertação (Mestrado em Geografia) - UNIVERSIDADE ESTADUAL DE LONDRINA - UEL. Londrina, 2016.

GUIMARÃES, R. B. Saúde urbana: velho tema, novas questões. Terra Livre, São Paulo, v. 17, p. 155-170, 2001.

IAPAR - Instituto Agronômico do Paraná -. Médias históricas em estações do IAPAR, 2013. Disponível em: <https://goo.gl/vRMAUi>. Acesso em 19 mar.2019.

IBGE - Instituto Brasileiro de Geografia e Estatísca. Malha digital municipal. 2015. Disponível em: $<$ https://mapas.ibge.gov.br/bases-e-referenciais/bases-cartograficas/malhas-digitais.html> Acesso em 12 dez. 2020.

ITCG / IAT - Instituto de Terras, Cartografia e Geologia / Instituto Água e Terra Paraná. Dados e Informações Geoespaciais Temáticos 2006-2008. Mapeamento Geológico do Paraná. 2006. Disponível em: <http://www.iat.pr.gov.br/Pagina/Dados-e-Informacoes-Geoespaciais-Tematicos>. Acesso em: 12 dez. 2020.

JULIÃO, R. P.; NERY, F.; RIBEIRO, J. L.; CASTELO BRANCO, M. e ZÊZERE, J. L. Guia metodológico para a produção de cartografia municipal de risco e para a criação de sistemas de informação geográfica (SIG) de base municipal. ANPC, Lisboa, 2009, 92 p.

LICHT, O. A. B. Geoquímica multielementar de superfície na delimitação de riscos e impactos ambientais, estado do Paraná, Brasil. In SILVA, C. R; FIGUEIREDO, B. R; CAPITANI, e. M; cunha, F. G. (Org.). Geologia Médica no Brasil: efeitos dos materiais e fatores geológicos na saúde humana e meio ambiente. Rio de Janeiro: CPRM- Serviço Geológico do Brasil, 2006. p. 21-35.

. Multiscale, multimedia and multi-element geochemical mapping of the State of Paraná, Brazil. Geochimica Brasiliensis 32(2): 209 - 242. DOI:10.21715/GB2358-2812.2018322209. 2018. https://doi.org/10.21715/GB2358-2812.2018322209

. ARIOLI, E. E. Mapa Geológico do Grupo Serra Geral - Nota Explicativa. Instituto de Terras, Cartografia e Geologia do Paraná (ITCG)/IAT. Curitiba, 316 p. 2018.

MAACK, R. Geografia Física do Paraná. 3. ed. Curitiba: Imprensa Oficial, 2002. 
MARIMON, Maria P. C. O flúor nas águas subterrâneas da formação Santa Cruz do Sul e

Venâncio Aires, RS, Brasil. 2006. Tese (Doutorado em Geociências). Departamento de Geoquímica. Universidade Federal do Rio Grande do Sul. Porto Alegre, 2006.

MARTINS, L. C.; WILDNER, W.; HARTMANN, L. A. Estratigrafia dos derrames da Província Vulcânica Paraná na região oeste do Rio Grande do Sul, Brasil, com base em sondagem, perfilagem gamaespectrométrica e geologia de campo. Pesquisas em Geociências. Porto Alegre, v. 38, n. 1, p. 15-27, jan./abr. 2011. https://doi.org/10.22456/1807-9806.23833

MILANI, E. J.; MELO, J. H. G.; SOUZA, P. A.; FERNANDES, L. A.; FRANÇA, A. B. Bacia do Paraná. Boletim de Geociências Petrobrás, Rio de Janeiro, v. 15, n. 2, mai/nov. 2007, p. 266-287.

MINEROPAR - Mineirais do Paraná S.A. -. Atlas Geoquímico do Estado do Paraná. Curitiba: MINEROPAR, 2001. 80p.

Mapa Geológico do Estado do Paraná 1:650.000. 2006. Disponível em: <http://www.iat.pr.gov.br/Pagina/Mapeamento-Geologico>. Acesso em:12/12/2020.

MORITA, M. C.; CARRILHO, A.; LICHT, O. A. B. Use of geochemistry data in the identification of endemic fluorosis areas. In: WORLD CONGRESS OF HEALTH AND URBAN ENVIROMENT, 1, 1998, Anais... Madrid, 1998.

OMS - Organização Mundial de Saúde. Aplicaciones de la epidemiología al estudio de los ancianos. Informe de un grupo científico de la OMS sobre la epidemiología del envejecimiento, Genebra,1984.

Elementos traços na nutrição e saúde humanas. Genebra: Rôca, 1969.

Environmental health criteria: principles and methods for the assesment of risk from essential trace elements, Geneva, 2002.

OUTERBRIDGE, T. Fluoridation campaign. Ecologist, v. 16, n.6, p. 230-237, 1986

PARANÁ (Estado). Secretaria de Saúde. Saúde bucal, 2013. Disponível em: <https://goo.gl/svw2tz>. Acesso em 19 mar 2019.

PICCIRILLO E. M.; COMIN-CHIARAMONTI; MELFI A. J.; STOLFA, D.; BELLIENI, G.; MARQUES, L. S.; GIARETTA, A.; NARDY, A. J. R.; PINESE, J. P. P.; RAPOSO, M. I. B.; ROISENBERG, A.

Petrichemistry of Continental Flood Basalt-Rhyolite Suites and Related Intrusives from the Paraná Basin (Brazil). In: PICCIRILLO, E. M.; MELFI, A. J. (eds.). The Mesozoic Flood Volcanism of the Paraná Basin: Petrogenetic and Geophysical Aspects. São Paulo, Instituto Astronômico e Geofísico Universidade de São Paulo. p. 107-156. 1988. https://doi.org/10.1007/978-94-015-7805-9 6

PINESE, J. P. P. Síntese Geológica da Bacia do Rio Tibagi. In: Moacyr E. Medri; Edmilson Bianchini; Oscar A. Shibatta; José A. Pimenta. (Org.). A Bacia do Rio Tibagi. 1ed. Londrina-PR: MC Gráfica Editora, 2002, v. 1, p. 21-38.

; ALVES, J. C.; LICHT, O. A. B.; PIRES, E. O.; MARAFON, E. Características geoquímicas naturais da água de abastecimento público da porção extremo norte do Estado do Paraná, Brasil. In: CONGRESSO BRASILEIRO DE GEOLOGIA, 41, João Pessoas. Anais... João Pessoa, 2002.

.; MARTINS JUNIOR, J. C. G. Riscos ambientais geogenéticos na utilização das águas subterrâneas para o consumo humano sem análise geoquímica prévia. In: CARVALHO, Márcia Siqueira de (Org.). Geografia, meio ambiente e saúde em Londrina. Londrina: Edições Humanidades, 2005, v. 1, p. 133-164.

.; GOLONO DE DEUS, A.; ALVES, J. C.; MORITA, M. C. Análise da distribuição espacial dos teores de flúor nas bacias hidrográficas do Norte do Paraná, Brasil e riscos à saúde coletiva. In: INTERNATIONAL CONGRESS ON RISKS, 4, 2017, Coimbra. Abstracts IV International Congress on Risks. Coimbra: Associação Portuguesa de Riscos, Prevenção e Segurança, 2017 b. v. 1. p. 353353.

; GUIMARAES, D. V. Principais Aspectos do Meio Físico no Município de Londrina, Paraná, Brasil. In: CUNHA, L.; YAMAKI, H. (Org.). Paisagem e Território. 1.ed. Londrina: EDUEL, 2018, v. 1, p. 89-108.

; ROSS, A.; ALVES, J. C. Paisagens e Territórios Urbanos de Risco à Saúde Bucal balizadas pelos Teores de Fluoretos Naturais em Águas Subterrâneas de Abastecimento Público em Londrina,

$\begin{array}{lllll}\text { Caminhos de Geografia } \quad \text { Uberlândia-MG } & \text { v. 22, n. } 81 \quad \text { jun./2021 } & \text { p. 88-105 } & \text { Página } 104\end{array}$ 
PR .(Brasil). In: Humberto Yamaki; Lucio Cunha. (Org.). Paisagem e Território: Expedições.

1ed.Londrina: EDUEL, 2019, v. 1, p. 63-75.

PIRES, E. O. Geografia da saúde e geologia médica como instrumentos de planejamento e gestão em saúde ambiental: o caso das anomalias de flúor e da fluorose dentária em ItambaracáPr. 2008. Dissertação (Mestrado em Geografia) - Centro de Ciências Exatas, Universidade Estadual de Londrina, Londrina.

QGIS PROJECT. Software QGIS versão 2.18 - Las Palmas. QGIS Association. Disponível em $<$ http://www.qgis.org>. Acesso em: 19 mar. 2019.

REBELO, F. Riscos naturais e acção antrópica. Coimbra, IUC, 2001, 274 p. (2ª edição revista e aumentada em 2003).

REBELO, F. Geografia Física e riscos naturais. Coimbra, IUC, 2010, 215 p. https://doi.org/10.14195/978-989-26-0188-5

REDDY, D. B.; RAO, C. M.; SARADA, D. Endemic fluorosis. J Indian Med Assoc, India, v. 53, p. 275-281, 1969.

ROSA FILHO, E. F.; HINDI, E. C.; MONTOVANI, L. E.; BITTENCOURT, A. V. L. Aquíferos do Estado do Paraná. Curitiba: Edição do Autor, 2011

SILVA, C. R.; FIGUEIREDO, B. R.; CAPITANI; E. M.; CUNHA, F. G. (Org.). Geologia médica no Brasil: efeitos dos materiais e fatores geológicos na saúde humana, animal e meio ambiente / Cássio Roberto da Silva (Ed.) ... [et al.]. — Rio de Janeiro: CPRM - Serviço Geológico do Brasil, 2006. 220 p.

STEFANO, T. M. The fluoridation research studies and the general practitioner. Bulletin of Hudson County Dental Society, 1954.

SUTTON, P. R. N. Fluoradation: a fifty-year old accepted but unconfirmed hypothesis. Med Hypotheses, v. 27, 1986, p. 153-156. https://doi.org/10.1016/0306-9877(88)90163-6

VELÁSQUEZ, L. N.; FANTINEL, L. M.; FERREIRA, F. E; CASTILHO, L. S; UHLEIN, A.; VARGAS, A. M. D.; ARANHA, P. R. A. Fluorose dentária e anomalias de flúor na água subterrânea no município de São Francisco, Minas Gerais, Brasil. In: SILVA, C. R; FIGUEIREDO, B. R; CAPITANI, E. M.; CUNHA, F. G. (Org.). Geologia Médica no Brasil: efeitos dos materiais e fatores geológicos na saúde humana e meio ambiente. Rio de Janeiro: CPRM- Serviço Geológico do Brasil, 2006. p. 110-117.

VIEGAS, A. R.; VIEGAS, I.; CASTELLANOS, R. A. Fluoretação da água de abastecimento público. Revista da Associação Paulista de Cirurgiões Dentistas, São Paulo, v. 41, n. 4, 1987, p.20022004.

ZIEGELBECKER, R. A critical review on the fluorine cáries problem. Fluoride. v. 3, p. 71-79, 1970.

Recebido em: 01/06/2020

Aceito para publicação em: 16/12/2020 